\title{
Research identify the group for lead - zinc ore type to prepare exploration in Ban Lim area, Caobang province, Vietnam
}

\author{
Luong Quang Khang ${ }^{1, *}$, Khuong The Hung ${ }^{1}$, Nguyen Phi Hung ${ }^{1}$, and Dang Minh Ton $^{2}$ \\ ${ }^{1}$ Hanoi University of Mining and Geology of Vietnam, 0084, Phovien Str., 18, Nam Tuliem Dis., \\ Vietnam \\ ${ }^{2}$ Department of resources, Tuyen Quang province, 0084, Y La Str., 18, Tuyen Quang Dis., Vietnam
}

\begin{abstract}
Ban Lim area, Caobang province has proposed high potential of lead-zinc resources, which have occurred in different geological formations. In this paper, based on the collecting, synthetics and processing geological data, especially applied mathematical methods to recognize studied objects of exploration process and quantitative description. The results show that the lead-zinc orebodies in Ban Lim area are mainly occurred in lens-shaped and distributed in layered surfaces of dolomitized limestone of Coc Xo formation. The average lead-zinc content of the orebodies is in a range from $3.27 \%$ to $8.33 \%$, its coefficient of variation $\left(V_{c}\right)$ is in a range from $13.71 \%$ (evenly) to $137.92 \%$ (very unevenly). On the whole, the lead-zinc contents of the orebodies in Ban Lim area mainly comply with the standard normal distribution. The average thicknesses of the orebodies are in a range from $0.92 \mathrm{~m}$ to $6.48 \mathrm{~m}$, its coefficient of variation $\left(V_{m}\right)$ is in the range from $8.7 \%$ (stable) to $132.95 \%$ (very unstable). Quantitative calculation results have shown that Ban Lim lead-zinc deposit belongs to group III of deposits. For the exploration of this type of minerals, it is recommended to use linear grid pattern. Appropriate exploration grid pattern for category 122 reserve is $(60-80) \times(30-40) \mathrm{m}$.
\end{abstract}

\section{Introduction}

Geological mapping works have revealed several lead-zinc ore deposits in the Caobang province. However, most of these deposits are proposed as small to medium in size, excepted for the Ban Lim area that is evaluated over prospective (D.Q. Binh, 2004; N.V. Phu, 2019). So far, there has not been any research projects that adequately and systematically mentioned the geological characteristics and lead-zinc mineralization in the study area. Especially, up to date insufficient intensive research on ore mineralization and geological parameters of lead-zinc orebodies, as well as establishing a mining exploration group and matched exploration grid for lead-zinc ore type in the area. In order to ensure reliability and effective documents of the lead-zinc exploration and establishing a mining group of lead-zinc deposit

\footnotetext{
* Corresponding author: hunguni@gmail.com
} 
and an exploration grid pattern in the Ban Lim area. In this research, the results of collecting, synthetics, processing geological data, and mathematical methods are utilized to investigate studied objects of exploration process and quantitative description.

According to Provisions of the Vietnam Ministry of Natural Resources and Environment (2006), deposits are categorized by their complexity, size, and shape. Based on this opinion they can be divided into four groups of mineral deposits. Group I deposits, the group is comprised of deposits that have no structural complexity, uniform thickness, homogeneous grades. They are often large deposits, simple in form, with uniform distribution of minerals. A normal density of drillholes allows the definition of a high level of 121 reserves. Group II deposits are more complex in structure, non-uniform thickness, significant grade variability. They are large deposits with different and sometimes complicated forms and uneven distribution of minerals. Only up to 121 category reserves may be defined with a normal grid of drillholes. Group III deposits - highly complex structure, significant variations in thickness and very uneven grade distribution. They are smaller sized deposits with uneven distribution of minerals. Drillholes can only establish 122 reserves. Finally, group IV deposits - extremely complex structure, extreme variations in thickness and in grade distribution. They are smaller sized deposits or small pocket deposits with even more complex shapes. Drilling in combination with underground workings is necessary to establish category 122 reserves.

\section{General geological features of Ban Lim area, Caobang province}

The lithology of the Ban Lim area composes mainly of carbonate intercalated with gray, light gray to dark-gray terrigenous sedimentary rocks that were suggested as early Devonian age and is termed as Coc Xo formation (N.V. Phu, 2019). In the center of Ban Lim area, effusive rocks of felsic and rhyolite (undefined age) are exposed in lens-shaped, extending in the northwest-southeast trending (Figure 1). Quaternary sediment is distributed along the river and Ban Lim valley.

Study on the structure of the Ban Lim area, previous work has proved a monoclinal structure extend in a northwest-southeast direction (P.Q. Tri, 2013). Three fault systems also have been mapped in the area (N.V. Phu, 2019), which are northwest-southeast, northeast-southwest, and near a west-east trending system. Of which, the northwestsoutheast fault system has been supported as the major faults and controlled the main structure of the Ban Lim area (N.V. Phu, 2019). Most of the lead-zinc orebodies discovered in the Ban Lim area are controlled by this fault system (P.Q. Tri, 2013; N.V. Phu, 2019). The northeast-southwest and west-east fault systems are younger and displaced the orebodies that make the area complicated.

\section{Methods}

Establishing a mining group of deposit and an exploration grid within a study area can be characterized by statistical measures and properties describing the pattern, as well as by indicators of more local properties of the orebodies as shape, morphology, and structure. The former can be described by a series of summary statistics providing information on the morphological and structural orebodies. Estimates of average mineral deposit parameters have been extensively used in quantitative mineral resource assessments to estimate numbers of exploration works in a study area based on statistical methods and the theory of random functions (Wellmer, 1998). In contrast, methods for establishing an exploration grid pattern have rarely been applied to investigate mineral deposit patterns (Saikia \& Sarkar, 2006). 


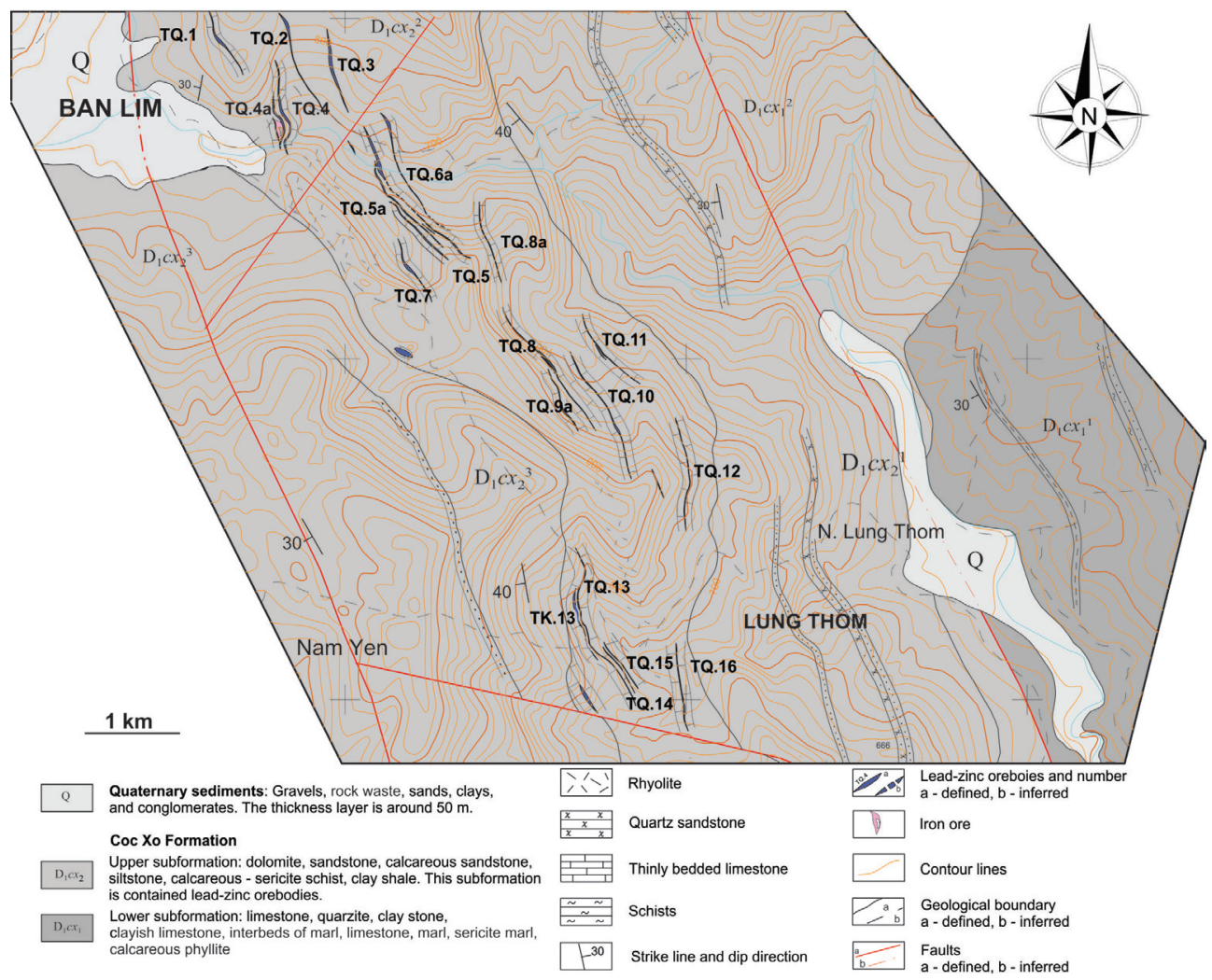

Fig. 1. Simplified geological map of Ban Lim area, Caobang province (modified from N.V. Phu, 2019).

On combination geological data that is collected, synthesized, and processed from previous documents, the authors have applied geomathematical methods in order to improve the efficiency of evaluation of lead-zinc mineralization characteristics in Ban Lim area.

\subsection{Establishing a mining group of deposit}

\subsubsection{One-dimensional statistical mechanics model}

This method is used in processing geochemical data for descriptive statistical distribution of geological parameters such as compositions, thickness, technical properties, and physical parameters of orebodies.

The purpose of this problem statement is to determine the average values, variance, coefficient of variation of geological parameters to ensure the truthfulness, efficiency and non-error in data processing, to ensure reliability. Based on the probability distribution function, it allows determining the probability of random numbers appearing in arbitrary selection range. The method provides a detailed content in Wellmer (1998).

\subsubsection{Morphology and structure of the orebodies}

Ore-bearing coefficients $\left(K_{p}\right)$ : As we already know, the ore-bearing coefficient is determined according to thickness, area and length of orebody. 
By calculating the orebody thickness:

$$
K_{p}^{m}=\frac{\sum_{i=1}^{N} m_{i}}{\sum_{i=1}^{N} M_{i}}
$$

where $m_{i}$ - thickness of payable ore determined in the i-th exploration work, $\mathrm{m} ; M_{i}$ thickness of lead - zinc ore bearing rock layer, $\mathrm{m} ; N$ - number of exploration projects.

By calculating the ore area:

$$
K_{p}^{S}=\frac{\sum_{i=1}^{N} S_{p}}{S}
$$

where $\sum_{i=1}^{N} S_{p}$ - total orebodies area limit in the exploration region, $\mathrm{m}^{2} ; N$ - number of orebodies; $S$ - area of the exploration object, $\mathrm{m}^{2}$.

By calculating the ore piece:

$$
K_{P}^{L}=\frac{\sum_{i=1}^{N} L_{P}}{\sum_{i=1}^{N} L_{c}}
$$

where $\sum_{i=1}^{N} L_{P}$ - total length of orebodies, $\mathrm{m} ; \sum_{i=1}^{N} L_{c}$ - total general length of the exploration lines, $\mathrm{m}$.

Coefficients of broken ore $\left(K_{n p}\right)$ is determined by formula:

$$
K_{n p}=\frac{i}{K_{p}^{m}}
$$

where $i$ - number of broken ore is determined by exploration lines section; $K_{p}^{m}$ - ore bearing coefficients.

Coefficients of morphological anisotropy $(\lambda)$ of orebodies on the mapping:

$$
\lambda=\frac{A}{B}
$$

with $A$ - orebody thickness is determined in mapping, $\mathrm{m} ; B$ - orebody width is determined in mapping, $\mathrm{m}$.

Coefficients of ore dressing $(\beta)$ is determined by formula:

$$
\beta=\frac{C_{t b}}{C_{C N}}
$$

with $C_{t b}$ - mean $\mathrm{Pb}+\mathrm{Zn}$ contents of payable orebodies, $\% ; C_{C N}-$ selected minimum economic content of ore, $\%$.

Boundary modules: are determined on the basis by comparing the actual circumference and a circumference of the orebody in geometric form. The complexity degree of orebody boundary is determined by the formula: 


$$
M_{K}=\frac{e \varphi}{4.7 a+1.5 \frac{L \varphi}{a}-1.77 \sqrt{L \varphi}}
$$

in which: $a$ - half of the longest boundary, $\mathrm{m} ; L \varphi$ - perimeter of the orebody is converted to ellipse; $e \varphi$ - actual circumference of orebody, $\mathrm{m}$.

Orebody shaped index $(\phi)$ is calculated as:

$$
\phi=\frac{V M_{K}}{K_{c c}}
$$

in which: $V$ - coefficient of variation of payable orebody thickness, $\% ; K_{c c}$ - coefficient of complexity orebody structure, $\%$.

$$
K_{c c}=1-\frac{m_{k} n_{k}}{m_{q} n_{q}}
$$

with $m_{k}$ - total mean thickness of intercalated layers in orebody, $\mathrm{m} ; n_{k}$ - total number of intercalated layers in orebody; $m_{q}$ - total mean thickness of ore beds, $\mathrm{m} ; n_{q}$ - total number of ore beds.

\subsection{Establishing an exploration grid pattern}

\subsubsection{Statistical methods}

For given area of estimation reserves, the errors of estimated metal reserves are determined as formulas:

$$
\begin{gathered}
\Delta_{p}=\sqrt{\Delta_{m}^{2}+\Delta_{c}^{2}+\Delta_{d}^{2}+\Delta_{s}^{2}} \\
\Delta_{x}=\frac{t V_{x}}{\sqrt{N}} \\
\Delta_{s}=\frac{S_{2}}{4 S_{1}} 100 \%
\end{gathered}
$$

where: $\Delta_{m}, \Delta_{c}, \Delta_{d}, \Delta_{s}$ - relative standard errors of mean thickness, mean content, orebody area, and mean bulk density of ore; $S_{1}$ - interpolated orebody area, $\mathrm{m}^{2} ; S_{2}$ - extrapolated orebody area, $\mathrm{m}^{2} ; \mathrm{t}$ - probability factor; $\mathrm{V}_{\mathrm{x}}$ - coefficient of variation of $\mathrm{x}$ value, $\% ; \mathrm{N}$ number of exploration works.

Relative standard errors of bulk density are common very least errors and skipping. For exploration data, resulted analysis of lead - zinc contents are generated gross errors and random, its lending to mean contents are determined as:

$$
\Delta_{c^{\prime}}=\sqrt{\Delta_{c}^{2}+\Delta_{p t}^{2}}
$$

with $\Delta_{p t}$ - random errors in sample analysis.

Estimation for density of exploration grid by mathematical statistics

Kazdan (1977) declared that, exploration results meet reliability requirement when error of the reserve parameters. 


$$
\sum \Delta=\sqrt{\Delta_{m}^{2}+\Delta_{c}^{2}+\Delta_{d}^{2}+\Delta_{s}^{2}} \leq \Delta_{c p} .
$$

with $\Delta_{c p}$ - allowable errors in sample analysis.

For group III deposits, in order to meet the requirement of calculating the category 122 reserves to ensure safety, it is necessary to select the relative reserves of allowable reserve according to the current regulations in the range of $30 \div 50 \%$. Therefore, the number of exploration works necessary to control orebodies can be determined by the formula:

$$
N \geq \frac{\left(V_{m}^{2}+V_{c}^{2}\right) t^{2}}{\Delta_{c p}^{2}}
$$

or following point reserves:

$$
N \geq \frac{V_{q}^{2} t^{2}}{\Delta_{c p}^{2}} .
$$

Where: $V_{m}, V_{c}, V_{q}$ - coefficients of variation in thickness, contents, and point reserves of estimated orebodies; $\Delta_{c p}{ }^{-}$permissible error $(30 \div 50 \%) ; t$ - probability factor ( $t=2$ corresponding to $P=0.95$ ). In fact, exploration often encounters orebody, which is often distorted, so many researchers recommend adding distortion coefficients to the orebody and taking the value of 0.15 . Therefore, the number of specific works is $1.15 \mathrm{~N}$.

Pogrebiski (1973) summed up that, mineral deposits have coefficient of variations in thickness and content over $80 \%$, the number of works calculated by statistical methods are often larger than reality. Conversely, if their coefficient of variations is less than $40 \%$, the number of calculation works will smaller. In case of the coefficient of variation changes in the range of $60 \div 80 \%$, statistical method usually gives good results. Therefore, density of exploration grid $\left(\mathrm{S}_{\mathrm{o}}\right)$ is calculated by the formula:

$$
S_{0}=\frac{S}{N}
$$

with $S_{o}=a \mathrm{x} b ; a=0.93 \sqrt{S_{0}} ; b=1.07 \sqrt{S_{0}}$. Where: $S$ - orebody area, $\mathrm{m}^{2} ; \mathrm{N}$ - number of exploration works; $a$ - strike line, $\mathrm{m} ; b$ - dip direction, $\mathrm{m}$.

\subsubsection{Applied methods of the theory of random functions}

Stable random function is featured by correlation function $K_{x}(\overrightarrow{\mathbf{h}})(\mathrm{h}$ - observed range), its depending to range, observed direction, and correlation function of norm - $R(h)$. The correlation function is determined by formula:

$$
K_{x}(\overrightarrow{\mathbf{h}})=\frac{1}{N-h} \sum_{i=1}^{N-h}\left[f\left(x_{i}\right)-E(X)\right]\left[f\left(x_{i+h}\right)-E(X)\right]
$$

with $\mathrm{f}\left(\mathrm{x}_{\mathrm{i}}\right)$ and $\mathrm{f}\left(\mathrm{x}_{\mathrm{i}+\mathrm{h}}\right)$ - values of spatial parameters at points of $\mathrm{x}_{\mathrm{i}}$ and $\mathrm{x}_{\mathrm{i}+\mathrm{h}}$ coordinates; $x_{i}$ value of $x$ at $i$ point; $x_{i+h}$ - value of $x$ at $i+h$ point; $X$ - average parameter in $x$ plane; $E(X)$ average spatial parameters in vollume.

Correlation function of norm is determined by the formula:

$$
R(h)=\frac{K_{x}(\overrightarrow{\mathbf{h}})}{\sigma_{x}^{2}}
$$


with $\sigma_{\mathrm{x}}$ - standard deviation following along the $\mathrm{x}$ axis.

In order to determine the size of influence zone $(H)$, or determined domain that allows interpolation, oscillation, and random transformation, we carry out construction of correlation plots.

$$
R^{*}(h)=e^{-\alpha \cdot h}
$$

with $\alpha$ - coefficient of variation in variability zone; $h$ - observed range.

Constructed plots of function:

$$
2 \sigma_{r}=\frac{2\left(1-R_{h}^{*}\right)}{\sqrt{N}}
$$

with $R_{h}^{*}$ - theoretical line of correlation plots.

Anisotropy coefficient (I) is defined as:

$$
I=\frac{H_{h d}}{H_{d p}}
$$

where: $H_{d p}$ - size of influence zone determined in strike line, $\mathrm{m} ; H_{h d}$ - size of influence zone determined in dip direction, $\mathrm{m}$.

Density of exploration grid $\left(S_{o}\right)$ is calculated by formula:

$$
S_{o}=H_{h d} \times H_{N}
$$

Number of required exploration works for assessment of orebody are defined as:

$$
N=\frac{S}{S_{0}}
$$

If coordinates $\left(x_{i}, y_{i}\right)$ of the collection point needs to convert it to coordinates $\left(x_{k}, y_{k}\right)$ of the grid cell, this conversion is done according to the formula:

$$
Z_{k}=\frac{\sum_{i=1}^{n} \frac{Z_{i}}{D_{i}^{k}}}{\sum_{i=1}^{n} \frac{1}{D_{i}^{k}}}
$$

With: $Z_{k}$ is average value of the study parameter at $\mathrm{k}$ point of the established base cell; $Z_{i}$ is value of the study parameter at i point; $D_{i}{ }^{k}$ is the distance from $\mathrm{k}$ point to closest point of $Z_{i}$ value.

\section{Results and Discussions}

\subsection{Characteristics of lead-zinc bodies}

Based on synthetic previous documents (Do Quoc Binh, 2004; Phung Quoc Tri, 2013; Nguyen Van Phu, 2019), and incorporating additional research materials, they allow further clarification of the distribution characteristics, structural and morphological characteristics, relationships and exist at depth of orebodies in the study area.

The results of this study indicate that the lead-zinc bodies are mainly lens-shaped, and bulge along the strike line of the orebody. Ore exposures are complicated and changing very much both quantity and shape. Lead-zinc ores occurred in associated with thick - to 
medium-bedded dolomitized limestone. Ore compositions are fairly evenly distributed along the strike line and dip direction of orebodies. Ore compositions are commonly an irregular lattice that is distributed in the layered surface of dolomitized limestone. Orebody dip to southwestward with dip angle varying from $35^{\circ}$ to $45^{\circ}$. The typical results of major orebodies are listed in Table 1.

Table 1. General characterictics of orebodies in Ban Lim area.

\begin{tabular}{|c|c|c|c|c|c|c|}
\hline \multirow{2}{*}{ No } & Orebodies & $\begin{array}{c}\text { Extend } \\
\text { along with } \\
\text { strike line } \\
(\mathrm{m})\end{array}$ & $\begin{array}{c}\text { Extend along } \\
\text { with dip } \\
\text { direction (from } \\
\text { m-to m) }\end{array}$ & $\begin{array}{c}\text { Average } \\
\text { thickness } \\
(\mathrm{m})\end{array}$ & Morphology & Strike/dip \\
\hline 1 & TQ.1 & 130 & $30-40$ & 0.99 & lens-shaped & $240 / 30$ \\
\hline 2 & TQ.2 & 180 & $40-55$ & 1.55 & lens-shaped & $240 / 48$ \\
\hline 3 & TQ.3 & 180 & 15 & 3.18 & lens-shaped & $250 / 15$ \\
\hline 4 & TQ.4 & 170 & 45 & 6.15 & lens-shaped & $230-240 / 41$ \\
\hline 5 & TQ.4a & 170 & $35-45$ & 6.48 & lens-shaped & $230-240 / 35$ \\
\hline 6 & TQ.5 & 135 & 40 & 5.98 & lens-shaped & $235-240 / 41$ \\
\hline 7 & TQ.5a & 135 & $40-45$ & 3.80 & lens-shaped & $230 / 36$ \\
\hline 8 & TQ.6 & 145 & $40-45$ & 3.42 & lens-shaped & $240 / 40$ \\
\hline 9 & TQ.6a & 155 & $30-50$ & 4.51 & lens-shaped & $240 / 37$ \\
\hline 10 & TQ.7 & 145 & $35-40$ & 2.60 & lens-shaped & $240 / 41$ \\
\hline 11 & TQ.8 & 145 & $35-40$ & 1.72 & lens-shaped & $230 / 42$ \\
\hline 12 & TQ.8a & 140 & 45 & 1.65 & lens-shaped & $240 / 43$ \\
\hline 13 & TQ.9 & 140 & 45 & 3.45 & lens-shaped & $230 / 42$ \\
\hline 14 & TQ.10 & 140 & 45 & 1.46 & lens-shaped & $240 / 40$ \\
\hline 15 & TQ.11 & 150 & 45 & 1.25 & lens-shaped & $230 / 50$ \\
\hline 16 & TQ.12 & 140 & $35-50$ & 1.35 & lens-shaped & $250 / 38$ \\
\hline 17 & TQ.13 & 170 & $35-45$ & 2.62 & lens-shaped & $250-280 / 40$ \\
\hline 18 & TQ.13a & 160 & $40-50$ & 3.01 & lens-shaped & $250 / 45$ \\
\hline 19 & TQ.14 & 160 & $40-50$ & 3.43 & lens-shaped & $250 / 45$ \\
\hline 20 & TQ.15 & 145 & 45 & 0.92 & lens-shaped & $250 / 43$ \\
\hline 21 & TQ.16 & 145 & 45 & 1.83 & lens-shaped & $250 / 40$ \\
\hline
\end{tabular}

\subsection{Estimation of exploration mining group for lead - zinc ore in Ban Lim area}

\subsubsection{Statistical characteristics of lead - zinc orebody parameters}

Statistical treatment of contents and thickness of the lead-zinc orebody in Ban Lim area is listed in table 2.

Table 2 shows that in all orebodies, the mean lead-zinc content is in a range from $3.27 \%$ to $8.33 \%$, its coefficient of variation $\left(V_{c}\right)$ is in the range from $13.71 \%$ (evenly) to $137.92 \%$ (very unevenly). On the whole, lead-zinc contents of the orebodies in Ban Lim area is mainly complied with standard normal distribution, except for orebodies of TQ.1 and TQ.6 are lognormal distribution.

As mentioned in table 3 , an average thickness of the lead-zinc orebodies vary from $0.92 \mathrm{~m}$ to $6.48 \mathrm{~m}$, its coefficient of variation $\left(V_{m}\right)$ is in the range of $8.7-132.95 \%$, their distributions belong to stable to very unstable. All orebody thicknesses mainly comply with the standard normal distribution. 
Table 2. Statistical characteristics of lead - zinc content of the orebodies.

\begin{tabular}{|c|c|c|c|c|c|c|}
\hline \multirow{2}{*}{ Orebody } & \multicolumn{7}{|c|}{$\begin{array}{c}\text { Pb }+ \text { Zn contents } \\
\text { Average } \\
\text { content } \\
(\%)\end{array}$} & $\begin{array}{c}\text { Variance } \\
\left(\sigma^{2}\right)\end{array}$ & $\begin{array}{c}\text { Coefficient of } \\
\text { variation } \\
\left(V_{c}, \%\right)\end{array}$ & $t_{A}$ & $t_{E}$ & $\begin{array}{c}\text { Distribution } \\
\text { pattern }\end{array}$ \\
\hline TQ.1 & 1.09 & 0.18 & 39.06 & 1.93 & 1.65 & $\begin{array}{c}\text { Lognormal } \\
\text { standard }\end{array}$ \\
\hline TQ.2 & 5.55 & 11.35 & 60.72 & -0.38 & -1.13 & Normal standard \\
\hline TQ.3 & 5.81 & 0.63 & 13.71 & 0.25 & 0.44 & Normal standard \\
\hline TQ.4 & 5.17 & 9.61 & 59.92 & 1.82 & 1.97 & Normal standard \\
\hline TQ.4a & 4.40 & 4.29 & 47.09 & 1.42 & 1.19 & Normal standard \\
\hline TQ.5 & 4.76 & 1.74 & 27.71 & -0.36 & 0.06 & Normal standard \\
\hline TQ.5a & 3.74 & 3.18 & 47.65 & 0.94 & -0.13 & Normal standard \\
\hline TQ.6 & 1.48 & 0.33 & 38.67 & 0.93 & -0.6 & $\begin{array}{c}\text { Lognormal } \\
\text { standard }\end{array}$ \\
\hline TQ.6a & 3.95 & 2.61 & 40.89 & -0.02 & -1.32 & Normal standard \\
\hline TQ.7 & 5.65 & 15.66 & 70.03 & 0.88 & -0.92 & Normal standard \\
\hline TQ.8 & 5.17 & 2.24 & 28.94 & -0.85 & 0.47 & Normal standard \\
\hline TQ.8a & 8.20 & 26.28 & 62.53 & 1.25 & 0.85 & Normal standard \\
\hline TQ.9 & 4.13 & 3.89 & 47.74 & 1.13 & 0.83 & Normal standard \\
\hline TQ.10 & 6.85 & 15.51 & 57.52 & 1.82 & 1.27 & Normal standard \\
\hline TQ.11 & 4.87 & 7.82 & 57.48 & 1.48 & 1.33 & Normal standard \\
\hline TQ.12 & 4.70 & 7.00 & 56.31 & 0.30 & -1.06 & Normal standard \\
\hline TQ.13 & 8.32 & 35.27 & 71.34 & 1.88 & -0.12 & Normal standard \\
\hline TQ.13a & 6.96 & 92.26 & 137.92 & 2.70 & 3.44 & Normal standard \\
\hline TQ.14 & 6.07 & 12.59 & 58.48 & 0.70 & 0.81 & Normal standard \\
\hline TQ.15 & 8.33 & 25.32 & 60.42 & 1.30 & 1.28 & Normal standard \\
\hline TQ.16 & 5.55 & 4.79 & 39.41 & 1.06 & 0.60 & Normal standard \\
\hline & & & & & & \\
\hline
\end{tabular}

With $t_{A}$ - standard for skewness $\left(t_{A}=\frac{A}{\sigma_{A}} ; A\right.$ - skewness $) ; t_{E}$ - standard for kurtosis $\left(t_{E}=\frac{E}{\sigma_{E}} ; \mathrm{E}-\right.$ kurtosis).

Table 3. Statistical characteristics of lead - zinc thickness of the orebodies in Ban Lim area.

\begin{tabular}{|c|c|c|c|c|c|c|}
\hline \multirow[b]{2}{*}{ Orebody } & \multicolumn{5}{|c|}{ True thickness parameters } & \multirow[b]{2}{*}{$\begin{array}{l}\text { Distribution } \\
\text { pattern }\end{array}$} \\
\hline & $\begin{array}{l}\text { Average } \\
(\mathrm{m})\end{array}$ & $\begin{array}{c}\text { Variance } \\
\left(\sigma^{2}\right)\end{array}$ & $\begin{array}{c}\text { Coefficient of } \\
\text { variation } \\
\left(V_{m}, \%\right)\end{array}$ & $t_{A}$ & $t_{E}$ & \\
\hline TQ.1 & 0.99 & 0.03 & 18.90 & 1.52 & 1.77 & Normal standard \\
\hline TQ.2 & 1.55 & 1.78 & 86.11 & 2.19 & 2.44 & Normal standard \\
\hline TQ.3 & 3.18 & 3.82 & 61.44 & 1.28 & 0.94 & Normal standard \\
\hline TQ.4 & 6.15 & 32.99 & 93.37 & 1.23 & $(0.48)$ & Normal standard \\
\hline TQ.4a & 6.48 & 37.25 & 94.22 & 0.76 & $(1.08)$ & Normal standard \\
\hline TQ.5 & 5.98 & 28.21 & 88.81 & 2.06 & $(0.14)$ & Normal standard \\
\hline TQ.5a & 3.80 & 3.99 & 52.58 & 0.17 & $(0.67)$ & Normal standard \\
\hline TQ.6 & 3.42 & 4.98 & 65.25 & 1.92 & 0.85 & Normal standard \\
\hline TQ.6a & 4.51 & 15.51 & 87.42 & 0.34 & $(1.09)$ & Normal standard \\
\hline TQ.7 & 2.60 & 2.34 & 58.78 & $(0.03)$ & $(1.38)$ & Normal standard \\
\hline TQ.8 & 1.72 & 0.12 & 20.45 & 1.23 & 1.28 & Normal standard \\
\hline
\end{tabular}


Table 3 (continued). Statistical characteristics of lead - zinc thickness of the orebodies in Ban Lim area.

\begin{tabular}{|c|c|c|c|c|c|c|}
\hline \multirow{2}{*}{ Orebody } & \multicolumn{5}{|c|}{ True thickness parameters } & \multirow{2}{*}{$\begin{array}{c}\text { Distribution } \\
\text { pattern }\end{array}$} \\
\cline { 2 - 6 } & $\begin{array}{c}\text { Average } \\
(\mathrm{m})\end{array}$ & $\begin{array}{c}\text { Variance } \\
\left(\sigma^{2}\right)\end{array}$ & $\begin{array}{c}\text { Coefficient of } \\
\text { variation } \\
\left(V_{m}, \%\right)\end{array}$ & $t_{A}$ & $t_{E}$ & Normal standard \\
\hline TQ.8a & 1.65 & 0.32 & 34.25 & 0.24 & 0.62 & $\begin{array}{c}\text { Lognormal } \\
\text { standard }\end{array}$ \\
\hline TQ.9 & 0.80 & 0.89 & 117.23 & 0.79 & -0.24 & Normal standard \\
\hline TQ.10 & 1.46 & 0.18 & 29.02 & 0.49 & $(0.57)$ & Nornal standard \\
\hline TQ.11 & 1.25 & 0.43 & 52.50 & 0.43 & $(0.74)$ & Normal \\
\hline TQ.12 & 1.35 & 0.06 & 17.69 & $(0.36)$ & $(1.06)$ & Normal standard \\
\hline TQ.13 & 2.62 & 7.48 & 104.34 & 4.26 & 5.81 & Normal standard \\
\hline TQ.13a & 3.01 & 1.22 & 36.75 & 0.61 & $(0.15)$ & Normal standard \\
\hline TQ.14 & 3.43 & 20.80 & 132.95 & 1.94 & 2.11 & Normal standard \\
\hline TQ.15 & 0.92 & 0.01 & 8.70 & $(0.64)$ & $(0.14)$ & Normal standard \\
\hline TQ.16 & 1.83 & 0.25 & 27.13 & 1.42 & 1.24 & Normal standard \\
\hline
\end{tabular}

\subsubsection{Characteristics of continuous mineralization}

Characteristics of continuous mineralization are one of the main factors that influence the degree of ease of accessible exploration geology. Therefore, a quantitative study of the continuity of lead-zinc ore mineralization by applying formulas (1), (2), and (3) are listed below.

The results are presented in Table 4 and 5 pointing out, lead-zinc ore mineralization is of discontinuous and continuous types, their coefficients of broken ore are complicated, especially in the orebody TQ.5 $\left(K_{n p}=108.11\right)$. Major lead-zinc bodies are commonly anisotropy shape (as seen in the TQ.3, TQ.4, TQ.4a, TQ.5, TQ.5a, TQ.6, TQ.6a, TQ.7, TQ.9, TQ13, TQ.14), excepted the orebodies TQ.1, TQ.2, TQ.6, TQ.7, TQ.8, TQ.8a, TQ.10, TQ.11, TQ.12, TQ.13a, TQ.15, and TQ.16. In most cases, lead-zinc contents belong to the base and medium, its coefficients of ore dressing are in a range from 0.94 (TQ.1) to 2.38 (TQ.13).

Table 4. Calculated results of lead-zinc ore-bearing coefficients in Ban Lim mine.

\begin{tabular}{|c|c|c|c|c|}
\hline No & Orebody & $K_{p}^{m}$ & $K_{p}^{S}$ & $K_{p}^{L}$ \\
\hline 1 & TQ.1 & 0.022 & 0.0004 & 0.021 \\
\hline 2 & TQ.2 & 0.023 & 0.0001 & 0.011 \\
\hline 3 & TQ.3 & 0.032 & 0.0002 & 0.010 \\
\hline 4 & TQ.4 & 0.108 & 0.0003 & 0.014 \\
\hline 5 & TQ.4a & 0.130 & 0.0002 & 0.007 \\
\hline 6 & TQ.5 & 0.009 & 0.0003 & 0.014 \\
\hline 7 & TQ.5a & 0.114 & 0.0002 & 0.010 \\
\hline 8 & TQ.6 & 0.222 & 0.0005 & 0.021 \\
\hline 9 & TQ.6a & 0.068 & 0.0002 & 0.013 \\
\hline 10 & TQ.7 & 0.039 & 0.0002 & 0.010 \\
\hline 11 & TQ.8 & 0.026 & 0.0001 & 0.010 \\
\hline 12 & TQ.8a & 0.016 & 0.0001 & 0.011 \\
\hline 13 & TQ.9 & 0.095 & 0.0002 & 0.013 \\
\hline 14 & TQ.10 & 0.029 & 0.0003 & 0.014 \\
\hline
\end{tabular}


Table 4 (continued). Calculated results of lead-zinc ore-bearing coefficients in Ban Lim mine.

\begin{tabular}{|c|c|c|c|c|}
\hline No & Orebody & $K_{p}^{m}$ & $K_{p}^{S}$ & $K_{p}^{L}$ \\
\hline 15 & TQ.11 & 0.019 & 0.0001 & 0.010 \\
\hline 16 & TQ.12 & 0.010 & 0.0001 & 0.014 \\
\hline 17 & TQ.13 & 0.111 & 0.0003 & 0.020 \\
\hline 18 & TQ.13a & 0.053 & 0.0002 & 0.009 \\
\hline 19 & TQ.14 & 0.043 & 0.0001 & 0.006 \\
\hline 20 & TQ.15 & 0.011 & 0.0001 & 0.011 \\
\hline 21 & TQ.16 & 0.018 & 0.0002 & 0.010 \\
\hline
\end{tabular}

Table 5. Calculated results of broken lead-zinc in orebodies.

\begin{tabular}{|c|c|c|c|c|}
\hline No & Orebody & $\begin{array}{c}\text { Coefficients } \\
\text { of broken ore }\end{array}$ & $\begin{array}{c}\text { Coefficients } \\
\text { of morphological } \\
\text { anisotropy }\end{array}$ & $\begin{array}{c}\text { Coefficients } \\
\text { of ore dressing }\end{array}$ \\
\hline 1 & TQ.1 & 45.02 & 0.49 & 0.94 \\
\hline 2 & TQ.2 & 43.05 & 0.77 & 1.59 \\
\hline 3 & TQ.3 & 31.42 & 1.06 & 1.66 \\
\hline 4 & TQ.4 & 9.29 & 2.05 & 1.48 \\
\hline 5 & TQ.4a & 7.72 & 1.62 & 1.26 \\
\hline 6 & TQ.5 & 108.11 & 1.99 & 1.36 \\
\hline 7 & TQ.5a & 8.78 & 1.27 & 1.48 \\
\hline 8 & TQ.6 & 4.50 & 1.98 & 1.13 \\
\hline 9 & TQ.6a & 14.80 & 1.50 & 1.61 \\
\hline 10 & TQ.7 & 25.64 & 1.65 & 1.48 \\
\hline 11 & TQ.8 & 38.84 & 0.95 & 1.34 \\
\hline 12 & TQ.8a & 60.73 & 0.91 & 1.96 \\
\hline 13 & TQ.9 & 10.55 & 1.72 & 1.39 \\
\hline 14 & TQ.10 & 34.31 & 0.58 & 1.34 \\
\hline 15 & TQ.11 & 53.18 & 0.63 & 2.38 \\
\hline 16 & TQ.12 & 98.66 & 0.68 & 1.99 \\
\hline 17 & TQ.13 & 8.98 & 1.75 & 1.73 \\
\hline 18 & TQ.13a & 18.99 & 0.86 & 2.38 \\
\hline 19 & TQ.14 & 23.32 & 1.91 & 1.59 \\
\hline 20 & TQ.15 & 87.22 & 0.61 & 0.83 \\
\hline 21 & TQ.16 & 54.58 & & \\
\hline
\end{tabular}

For investigated lead - zinc orebodies, we are going to estimate degree of broken ore, morphological anisotropy, and coefficients of ore dressing by applying formulas (4), (5), and (6).

\subsubsection{Complexity degree of orebody boundary module and orebody shaped index}

Applying formulas (7), (8), and (9) are estimated shapes, strike, and dip formats, complexity degree of structural orebodies. Calculated results of the complexity degree of the orebody boundary module and orebody shaped index are listed in Table 6.

Table 6 shows the complexity of lead-zinc orebodies, it varies from simple to complex, its shaped index also varies from simple to complex. In the Ban Lim area, research results on the quantitative changes of lead-zinc ore mineralization point out the thickness of orebodies are in medium to small size, its shape changes from relatively complicated to 
more complicated. Coefficients of thickness variation of orebodies are stable to unstable types with discontinuous mineralization. Lead-zinc contents of Ban Lim deposit are even to unevenly distribution, they also belong to base and medium contents, and covered by burden. Orebodies are relatively gentle dips. Based on the characteristics of the Ban Lim lead-zinc orebodies, and in comparison with the Vietnam Ministry of Natural Resources and Environment (06/2006/QD-BTNMT) we, therefore, categorize the Ban Lim lead-zinc deposit to group III deposits.

Table 6. Complexity degree of orebody boundary module and orebody shaped index.

\begin{tabular}{|c|c|c|c|c|c|}
\hline No & Orebody & Area $\left(\mathrm{m}^{2}\right)$ & $\begin{array}{c}\text { Orebody } \\
\text { boundary }\end{array}$ & $\begin{array}{c}\text { Complexity } \\
\text { degree }\end{array}$ & $\begin{array}{c}\text { Shaped } \\
\text { index }\end{array}$ \\
\hline 1 & TQ.1 & $1,386.00$ & $1,053.00$ & 0.94 & 0.021 \\
\hline 2 & TQ.2 & 482.40 & 622.60 & 1.12 & 0.026 \\
\hline 3 & TQ.3 & 778.60 & 478.40 & 0.94 & 0.030 \\
\hline 4 & TQ.4 & $1,114.00$ & 589.70 & 0.82 & 0.103 \\
\hline 5 & TQ.4a & 661.50 & 363.30 & 0.97 & 0.126 \\
\hline 6 & TQ.5 & $1,080.00$ & 814.30 & 1.10 & 0.019 \\
\hline 7 & TQ.5a & 771.60 & 607.40 & 1.19 & 0.136 \\
\hline 8 & TQ.6 & $1,762,00$ & $1,023.00$ & 0.91 & 0.202 \\
\hline 9 & TQ.6a & 774.60 & 697.80 & 1.04 & 0.070 \\
\hline 10 & TQ.7 & 679.20 & 436.50 & 0.82 & 0.032 \\
\hline 11 & TQ.8 & 307.50 & 501.70 & 0.94 & 0.024 \\
\hline 12 & TQ.8a & 475.20 & 525.50 & 0.91 & 0.015 \\
\hline 13 & TQ.9 & 562.60 & 717.20 & 1.07 & 0.131 \\
\hline 14 & TQ.10 & 924.50 & 887.70 & 1.20 & 0.035 \\
\hline 15 & TQ.11 & 393.30 & 544.70 & 1.07 & 0.020 \\
\hline 16 & TQ.12 & 471.30 & 683.60 & 0.96 & 0.010 \\
\hline 17 & TQ.13 & 939.10 & $1,059.00$ & 0.98 & 0.155 \\
\hline 18 & TQ.13a & 711.30 & 447.40 & 0.92 & 0.048 \\
\hline 19 & TQ.14 & 268.60 & 335.90 & 1.02 & 0.059 \\
\hline 20 & TQ.15 & 266.60 & 395.70 & 0.71 & 0.008 \\
\hline 21 & TQ.16 & 549.30 & 523.20 & 0.98 & 0.018 \\
\hline & & & & & \\
\hline
\end{tabular}

\subsubsection{Definition of exploration grid pattern for Ban Lim lead-zinc deposit}

The definition of rational exploration grid also known as optimization of exploration grid is done on the basis of the documents of exploration geological parameters. They are important to consider the explorer objects and depends on mining-geological structure characteristics. In most cases, point reserves (meters, \%) can be used as the key of geological parameters. If the thickness or important elements of orebodies are the largest variations, the basis for selecting the exploration grid will based on the characteristics of the largest orebody.

\section{a. Evaluating the effectiveness of exploration system}

Statistical method: Relative errors of lead - zinc orebodies are calculated by equations (10), (11), (12), and (13). Result calculations are listed in Table 7.

Table 7 shows that, lead-zinc reserve of orebodies (TQ.4, TQ.4A, TQ.5, TQ.5A, TQ.6, TQ.7, TQ.9, TQ.9A, TQ.13) have an error of less than $50 \%$, calculated in accordance with category 122 reserves. Other ones have an error greater than $50 \%$, stratified category 333 resources. Wherefore, the exploration grid pattern has been constructed for lead-zinc ore of Ban Lim deposit meeting the calculation of category 122 reserves and natural 
category 333 resources that is standardized by Vietnam Ministry of Natural Resources and Environment (2006).

Table 7. Relative errors of lead-zinc ore reserves of orebodies.

\begin{tabular}{|c|c|c|c|c|c|}
\hline \multirow{2}{*}{ No } & \multirow{2}{*}{ Orebody } & \multicolumn{4}{|c|}{ Relative errors (\%), $t=2$} \\
\cline { 3 - 6 } & & $\Delta_{s}$ & $\Delta_{m}$ & $\Delta_{c}$ & $\Delta_{p}$ \\
\hline 1 & TQ.1 & 1.34 & 70.58 & 45.30 & 83.87 \\
\hline 2 & TQ.2 & 0.66 & 70.31 & 49.57 & 86.03 \\
\hline 3 & TQ.3 & 2.92 & 61.44 & 13.71 & 63.02 \\
\hline 4 & TQ.4 & 2.45 & 12.60 & 36.69 & 38.87 \\
\hline 5 & TQ.4a & 0.79 & 66.63 & 33.30 & 74.49 \\
\hline 6 & TQ.5 & 1.27 & 38.76 & 12.09 & 40.62 \\
\hline 7 & TQ.5a & 0.73 & 30.36 & 27.51 & 40.98 \\
\hline 8 & TQ.6 & 1.41 & 25.59 & 25.09 & 35.87 \\
\hline 9 & TQ.6a & 1.08 & 71.38 & 33.39 & 78.81 \\
\hline 10 & TQ.7 & 0.64 & 16.70 & 23.63 & 28.94 \\
\hline 11 & TQ.8 & 1.14 & 47.99 & 57.18 & 74.66 \\
\hline 12 & TQ.8a & - & 34.25 & 62.53 & - \\
\hline 13 & TQ.9 & 1.10 & 20.52 & 40.68 & 45.57 \\
\hline 14 & TQ.10 & 0.83 & 67.59 & 28.79 & 73.47 \\
\hline 15 & TQ.11 & 0.66 & 42.86 & 46.93 & 63.56 \\
\hline 16 & TQ.12 & 0.68 & 20.42 & 65.02 & 68.15 \\
\hline 17 & TQ.13 & 0.64 & 27.13 & 39.41 & 47.85 \\
\hline 18 & TQ.14 & - & 118.91 & 52.31 & - \\
\hline 19 & TQ.15 & 0.27 & 7.78 & 54.04 & 54.60 \\
\hline 20 & TQ.16 & 0.67 & 50.61 & 34.61 & 61.31 \\
\hline
\end{tabular}

b. Density estimation for exploration grid

Statistical methods: Density of exploration grid is estimated by formulas (14), (15), $(15 \mathrm{a} \& \mathrm{~b})$, its calculated results are presented in Table 8 .

Table 8. Density of exploration grid based on the statistical method.

\begin{tabular}{|c|c|c|c|c|c|}
\hline \multirow[b]{2}{*}{ No } & \multirow[b]{2}{*}{ Orebody } & \multicolumn{2}{|c|}{ Distance (m) } & \multirow[b]{2}{*}{ Density $\left(\mathrm{m}^{2}\right)$} & \multirow{2}{*}{$\begin{array}{l}\text { Number of } \\
\text { exploration, } \\
\text { works } / \mathrm{km}^{2}\end{array}$} \\
\hline & & $\begin{array}{c}a-\text { strike } \\
\text { line }\end{array}$ & $\begin{array}{c}b-\operatorname{dip} \\
\text { direction }\end{array}$ & & \\
\hline 1 & TQ.4 & 70 & 40 & 2800 & 357 \\
\hline 2 & TQ.5 & 75 & 44 & 3300 & 303 \\
\hline 3 & TQ.5A & 70 & 40 & 2800 & 357 \\
\hline 4 & TQ.6 & 80 & 45 & 3600 & 278 \\
\hline 5 & TQ.7 & 80 & 40 & 3200 & 313 \\
\hline 6 & TQ.9 & 75 & 40 & 3000 & 333 \\
\hline 7 & TQ.13 & 70 & 40 & 3200 & 357 \\
\hline
\end{tabular}

Calculated results show that exploration grid of lead-zinc deposit is recommended to use a linear grid. The line spacing is selected to be $80 \mathrm{~m}$, or even better $70 \mathrm{~m}$, and the spacing between the points to be $45 \mathrm{~m}$ or even better $40 \mathrm{~m}$. The number of exploration works varies from 303 to 357 works $/ \mathrm{km}^{2}$.

The theory of stable random functions

Geological parameters of the orebody have a certain relationship, which is closely related to the distance between exploration works. Based on that properties, selecting the spacing density of works is a very important issue of a rational exploration grid. Because of 
the exploration conditions (density of observation points, outcrops, exploration works) are not evenly distributed over a certain geometric grid, therefore, it is necessary to convert the actual collected value to each point of the base grid cells for each region by the formula (19). The line spacing is selected to be $80 \mathrm{~m}$, and the spacing between the points to be $40 \mathrm{~m}$.

Based on the original and converted documents, to ensure accuracy of the method, we carry out the calculation of the autocorrelation radius $\mathrm{R}(\mathrm{h})$ following strike line and dip directions for content parameters of orebodies TQ.5, TQ.6 and T.13, they are the biggest ones in the study area.

After establishing the experimental autocorrelation radius $R(h)$, we apply formulas (16), (17) and (18) to conduct modeling, its meaning is induction experimental lines $R(h)$ to theoretical line $R^{*}(h)$, construct plots and calculated size of influence zone $(H)$ determined in strike line and in dip direction (Figures $2,3 \& 4$ ).

The obtained results showed that the line spacing is selected to be $70 \mathrm{~m}$ or even better $60 \mathrm{~m}$, and the spacing between the points to be $35 \mathrm{~m}$ or even better $30 \mathrm{~m}$. The number of exploration works varies from 420 to 556 works $/ \mathrm{km}^{2}$.

Combining calculated results between the statistical and stable random methods allow detected exploration grid for category 122 reserve, the line spacing is selected to be $60 \div 80 \mathrm{~m}$, and the spacing between the points to be $30 \div 40 \mathrm{~m}$ (Table 10 )

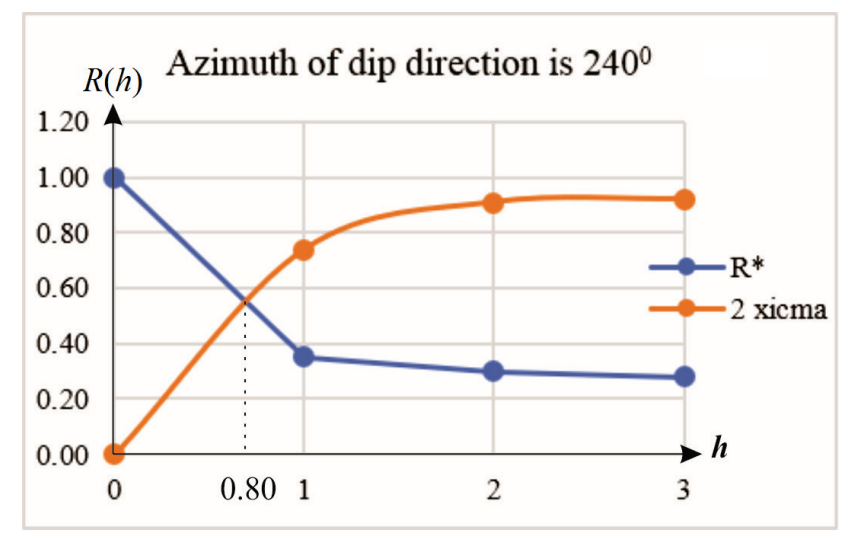

$h=0.80 ; H=32 \mathrm{~m}$

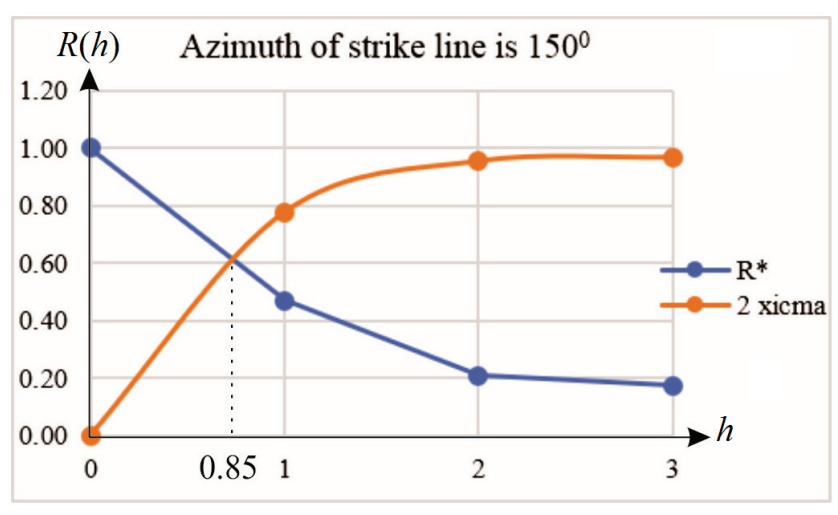

$$
h=0.85 ; H=68 \mathrm{~m}
$$

Fig. 2. Autocorrelation plots $R(h)$ of the TQ.5 orebody: $\mathrm{R}^{*}$ - theoretical line of correlation plots; 2 xicma - experimental lines. 


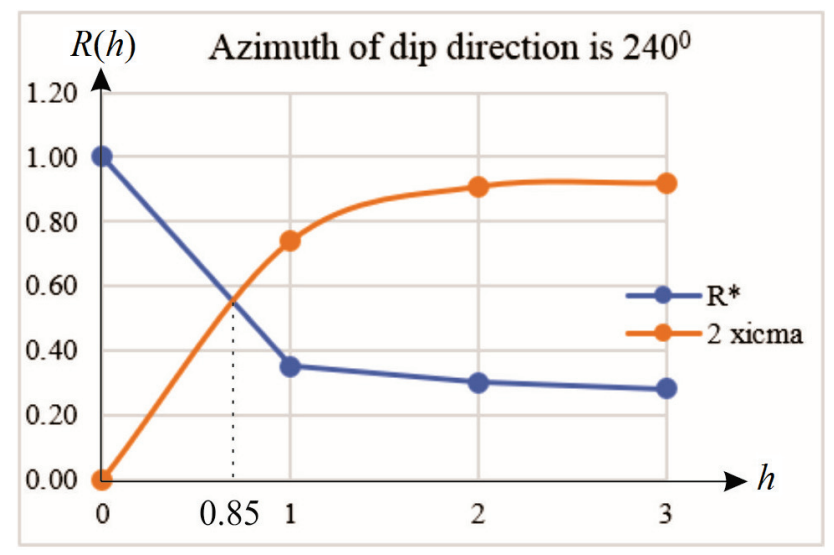

$h=0.85, H=34 \mathrm{~m}$

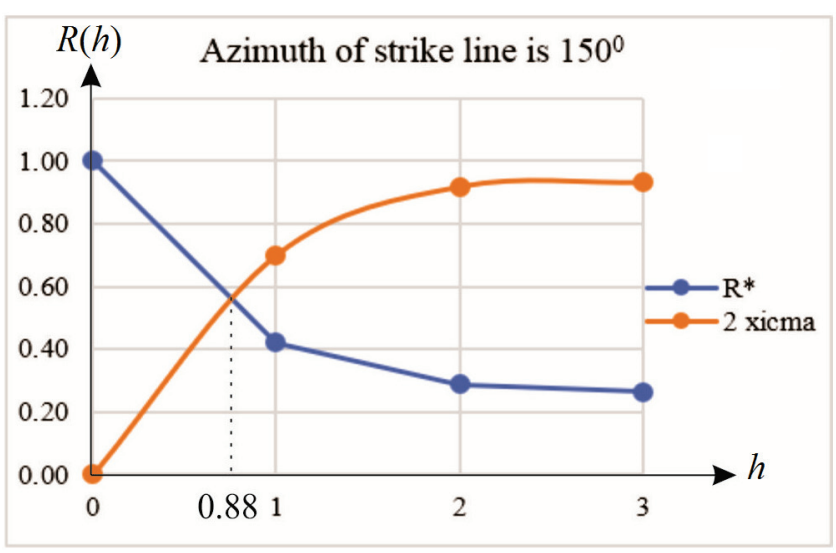

$$
h=0.88, H=70 \mathrm{~m}
$$

Fig. 3. Autocorrelation plots $R(h)$ of the TQ.6 orebody; R* - theoretical line of correlation plots; 2 xicma - experimental lines.

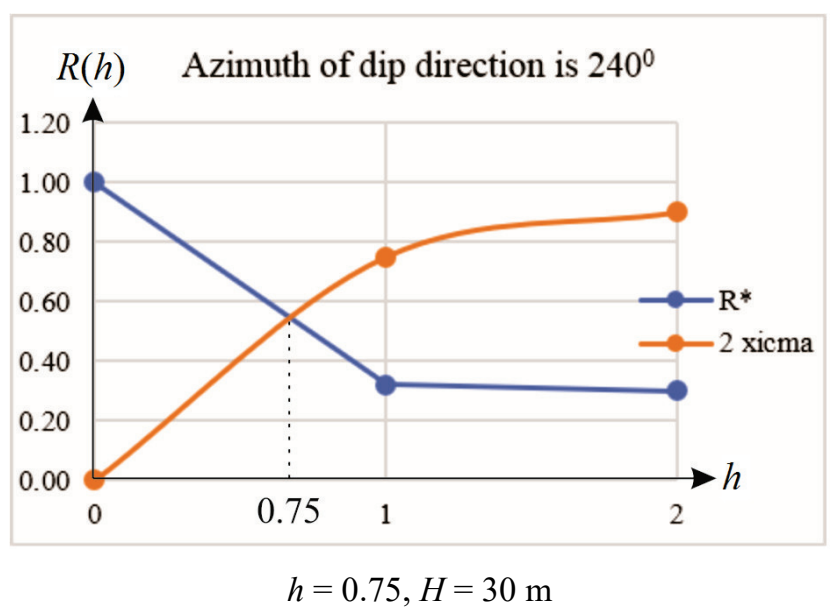

Fig. 4. Autocorrelation plots $R(h)$ of the TQ.13 orebody; R* - theoretical line of correlation plots; 2 xicma - experimental lines. 


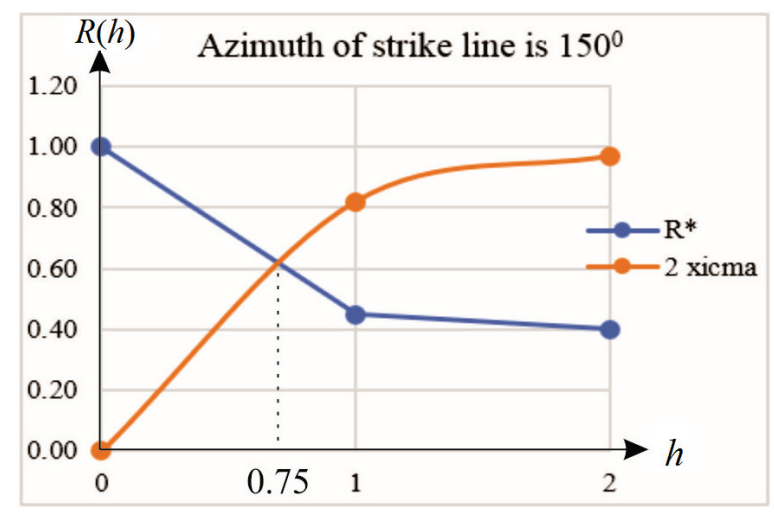

$h=0.75, H=60 \mathrm{~m}$

Fig. 4 (continued). Autocorrelation plots $R(h)$ of the TQ.13 orebody; $\mathrm{R}^{*}$ - theoretical line of correlation plots; 2 xicma - experimental lines.

Table 9. Density of exploration grid based on the theory of stable random function.

\begin{tabular}{|c|c|c|c|c|c|}
\hline \multirow{2}{*}{ Orebody } & \multirow{2}{*}{$\begin{array}{c}\text { Anisotropy } \\
\text { index }\end{array}$} & \multicolumn{2}{|c|}{ Distance $(\mathrm{m})$} & \multirow{2}{*}{ Sensity } & $\begin{array}{c}\text { Number of } \\
\text { exploration } \\
\text { works } / \mathrm{km}^{2}\end{array}$ \\
\cline { 3 - 4 } & & 68 & Dip direction & & \\
\hline TQ.5 & 0.47 & 72 & 2176 & 460 \\
\hline TQ.6 & 0.49 & 70 & 34 & 2380 & 420 \\
\hline TQ.13 & 0.46 & 60 & 30 & 1800 & 556 \\
\hline
\end{tabular}

Table 10. Exploration grid determined for reserves level 122.

\begin{tabular}{|c|c|c|c|}
\hline \multirow{2}{*}{ Orebody } & \multicolumn{2}{|c|}{ Distance $(\mathrm{m})$} & \multirow{2}{*}{$\begin{array}{c}\text { Number of } \\
\text { exploration works } / \mathrm{km}^{2}\end{array}$} \\
\cline { 2 - 3 } & Strike line & Dip direction & 408 \\
\hline TQ.5 & $70 \div 75$ & $35 \div 45$ & 408 \\
\hline TQ.6 & $70 \div 80$ & $35 \div 45$ & 556 \\
\hline TQ.13 & $60 \div 70$ & $30 \div 40$ & $408 \div 556$ \\
\hline General grid & $60 \div 80$ & $30 \div 40$ & \\
\hline
\end{tabular}

\section{Conclusions}

Research results show that lead-zinc orebodies in the Ban Lim area are mainly lens-shaped, fully distributed in the layered surfaces of dolomitized limestone of the Coc Xo formation. Average lead-zinc contents in the orebodies varied from $3.27 \%$ to $8.33 \%$, its coefficient of variation $\left(V_{c}\right)$ is in the range from $13.71 \%$ (evenly) to $137.92 \%$ (very unevenly), most of them can be inductive to the normal standard distribution. Average thickness of lead-zinc bodies is in a range from $0.92 \mathrm{~m}$ to $6.48 \mathrm{~m}$, its coefficient of variation $\left(V_{m}\right)$ is in the range from $8.7 \%$ (stable) to $132.95 \%$ (very unstable).

Based on quantitative calculation results and in comparison with Decision of the Vietnam Ministry of Natural Resources and Environment (06/2006/QD-BTNMT) have established the Ban Lim lead-zinc deposit belonging to group III deposits. For exploration of this type of minerals, it is recommended to use the linear grid pattern. Appropriate exploration grid pattern for category 122 reserve is $(60 \div 80) \mathrm{m} \times(30 \div 40) \mathrm{m}$. It means that the line spacing of the exploration grid is selected to be $80 \mathrm{~m}$ or even better $60 \mathrm{~m}$, and the spacing between the points to be $40 \mathrm{~m}$ or even better $30 \mathrm{~m}$. These calculated results are documented foundations that allow suggesting a mining group of deposit and an 
exploration grid pattern for lead-zinc ore in Ban Lim area and other lead-zinc deposits occurring in similar geological settings.

\section{References}

1. D.Q. Binh (ed.). Report on prospective setting of lead-zinc, gold and accompanying minerals in Phia Da - Na Cang area. Vietnam Institute of Geosciences and Mineral resources (in Vietnamese) (2004)

2. A.B. Kazdan. Prospecting and exploration of mineral deposits. Nedra Publishers, Moscow (in Russian) (1997)

3. N.V. Phu (ed.). Report on exploration of lead - zinc deposit in Ban Lim area, Thai Hoc village, Bao Lam district and Son Lo village, Bao Lac district, Caobang province. Dong Bac Geological Division (in Vietnamese) (2019)

4. P.Q. Tri (ed.). Report on prospective evaluation of lead-zinc ores in Ban Lim - Phi Dam area, Caobang - Bac Kan province. General Department of Geology and Minerals of Vietnam (in Vietnamese) (2013)

5. E.O. Pogrebiski. Prospecting and exploration of mineral deposits. Nedra Publishers, Moscow (in Russian) (1973)

6. K. Saikia, B.C. Sarkar. Exploration drilling optimisation using geostatistics: a case in Jharia Coalfield, India. Applied Earth Science, vol. 115, No. 1, 13-25 (2006)

7. Vietnam Ministry of Natural Resources and Environment. Decision of Promulgating the Regulation on classification of solid-mineral deposits and resources (Number: 06/2006/QD-BTNMT), Hanoi, June 07, 2006 (in Vietnamese) (2006)

8. F.W. Wellmer. Statistical evaluations in exploration for mineral deposits. Springer Verlag Berlin Heidelberg, Printed in Germany (1998) 